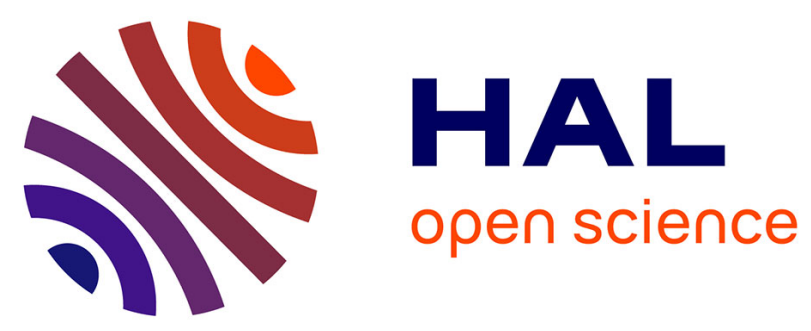

\title{
A NOVEL WAFER CAGE FOR BETTER UNIFORMITY OF PHOSPHORUS DOPED SILICON LAYERS : EXPERIMENTAL STUDY AND MODELLING \\ C. Azzaro, P. Duverneuil, J. Couderc
}

\section{To cite this version:}

C. Azzaro, P. Duverneuil, J. Couderc. A NOVEL WAFER CAGE FOR BETTER UNIFORMITY OF PHOSPHORUS DOPED SILICON LAYERS : EXPERIMENTAL STUDY AND MODELLING. Journal de Physique IV Proceedings, 1991, 02 (C2), pp.C2-71-C2-78. 10.1051/jp4:1991208 . jpa00249775

\section{HAL Id: jpa-00249775 https://hal.science/jpa-00249775}

Submitted on 1 Jan 1991

HAL is a multi-disciplinary open access archive for the deposit and dissemination of scientific research documents, whether they are published or not. The documents may come from teaching and research institutions in France or abroad, or from public or private research centers.
L'archive ouverte pluridisciplinaire HAL, est destinée au dépôt et à la diffusion de documents scientifiques de niveau recherche, publiés ou non, émanant des établissements d'enseignement et de recherche français ou étrangers, des laboratoires publics ou privés. 


\title{
A NOVEL WAFER CAGE FOR BETTER UNIFORMITY OF PHOSPHORUS DOPED SILICON LAYERS : EXPERIMENTAL STUDY AND MODELLING
}

\author{
C. AZZARO, P. DUVERNEUIL and J.P. COUDERC \\ Laboratoire de Génie Chimique, LGC-URA 192 du CNRS, ENSIGC, \\ Chemin de la Loge, F-31078 Toulouse cedex, France
}

\begin{abstract}
The deposition of in situ phosphorus doped polycrystalline silicon, an operation which involves complex physico-chemical phenomena, has been treated via both a modeling and an experimental approach. This analysis has contributed to provide better insights in the mechanism of phosphorus doped polysilicon deposition and has helped to design a new kind of a wafers cage, improving considerably the growth rate uniformity on each substrate.
\end{abstract}

\section{1.-Introduction}

The deposition of phosphorus doped polycrystalline silicon plays a major role in the fabrication of n-type polysilicon films. In conventional processes, the layer elaboration involves two steps: first, polysilicon is deposited undoped from a pure silane $\left(\mathrm{SiH}_{4}\right)$ source and subsequently, doped either by diffusion or ion implantation. Thus, the fabrication sequence implies at least two different equipments. As a consequence, interest has arisen in in situ doping, which offers the advantage of coupling these two steps in a single equipment, the most commonly used being the tubular horizontal hot walls reactor.

Although in situ doping is straightforward in concept, the addition of phosphine $\left(\mathrm{PH}_{3}\right)$ to silane strongly affects the deposition phenomenon $/ 1,2,3,4,5 /$ :

1- Decreases in growth rates ranging from a factor 2 to 20 have been reported, even with the low concentrations of phosphine involved.

2- Important radial non uniformities have been observed, creating an overdeposited ring at the wafer edge and leading to the famous "bull's eye effect".

3- The deposition rate increases rapidly with the interwafers distance, which is not the case when depositing pure silicon.

These difficulties are responsible for the relative low level of development of the in situ technique at the industrial scale, the microelectronics industry requiring stringent specifications on deposition uniformity, across each wafer, from wafer to wafer in a given batch, and from batch to batch as well. To avoid the bull's eye effect, practicians usually resort to cages, i.e. cylindrical internals, which are displayed around the wafers line, creating a stagnant volume exchanging gases with the annular zone only through circular holes or rectangular thin slots. When these cages have been conveniently organized, the bull's eye effect is no longer observed. But these cages are difficult to design as this procedure has, till now, only been done by trial and error adjustments. Furthermore, it has been experimentally observed that the presence of a cage increases markedly the level of solid 
particles. Finally, the last major drawback is that their use is generally not compatible with an automatic wafer handling $/ 6,7 \%$.

This article will be divided in three parts:

1)-First, the general philosophy of a $2 \mathrm{D}$-simulation model will be recalled, and a few examples of results which provide qualitative information on all these phenomena will be discussed;

2)- Second, an experimental study will give additional information;

3)-Third, the combination of these two approaches will suggest directions in which practical solutions can probably be found. Our work in this field is far from being complete but, as it will be seen in the following, the first results obtained seem promising.

\section{2.- Modelling of in situ phosphorus doped silicon deposition}

Several analysis of the complex physicochemical mechanisms involved during in situ phosphorus doped silicon deposition and its modelling can be found in the literature /8-11, for example/. A detailed discussion of all these works lies out of the scope of the present article which simply recalls the principles necessary for a general understanding of the rest of the paper and uses a few results of a $2 \mathrm{D}$-model that the authors have recently developed and presented elsewhere $/ 12,13 /$. In brief, the phenomena and the assumptions involved in the 2D-model are:

\section{2.- 1 Chemical mechanisms}

It is important to mention that homogeneous as well as heterogeneous reactions have been taken into account in the model $/ 12,13,14 /$.

Concerning silane pyrolysis, let us briefly recall that the study of silane chemistry has put in evidence the following reactions:

$$
\begin{gathered}
\mathrm{SiH}_{4} \leftrightarrow->\mathrm{SiH}_{2}+\mathrm{H}_{2} \\
\mathrm{SiH}_{2}+\mathrm{SiH}_{4} \ll->\mathrm{Si}_{2} \mathrm{H}_{6} \\
\mathrm{Si}_{\mathbf{n}} \mathrm{H}_{2 \mathrm{n}+2}+\mathrm{SiH}_{2}<->\mathrm{Si}_{\mathbf{n}+1} \mathrm{H}_{2 \mathrm{n}+4}
\end{gathered}
$$

It is to be noted that the concentration of silanes decreases rapidly, as their order increases; this is why only the two first reactions of the series have been taken into account in the model: silylene constitutes an extremely reactive radical and disilane is an efficient source for silylene.

The disturbing characteristics observed in presence of phosphine can be explained by the inhibiting effect of this dopant, once adsorbed on the surface of wafers $/ 15 /$. The electronical structure of the silicon-phosphorus bond increases the local charge of electrons in the neighbouring of the silicon atoms. As a consequence, the surface coverage by hydrogen increases and, hence, the number of active sites for silane adsorption decreases; the phosphorus atoms, integrated in the crystalline network, passivate the surface towards silane adsorption, explaining the reduction of the silicon growth rate. This justifies why the silylene mechanism, which plays a secondary role during pure polysilicon deposition becomes predominant in presence of phosphine.

Concerning surface reactions, only silicon depositions from silane and silylene have been considered in the model $/ 14 \%$.

\section{2.- 2 Model structure $/ 14 /$}

Only a representative part, i.e an interwafers space and the corresponding reactor wall has been taken into account in the $2 \mathrm{D}$ model developed in this work. In this volume (see Fig. 1), the continuity and Navier-Stokes equations on one hand and the mass transfer equations for each gaseous species on the other hand, have been solved separately, by a finite difference procedure, with appropriate boundary conditions. 


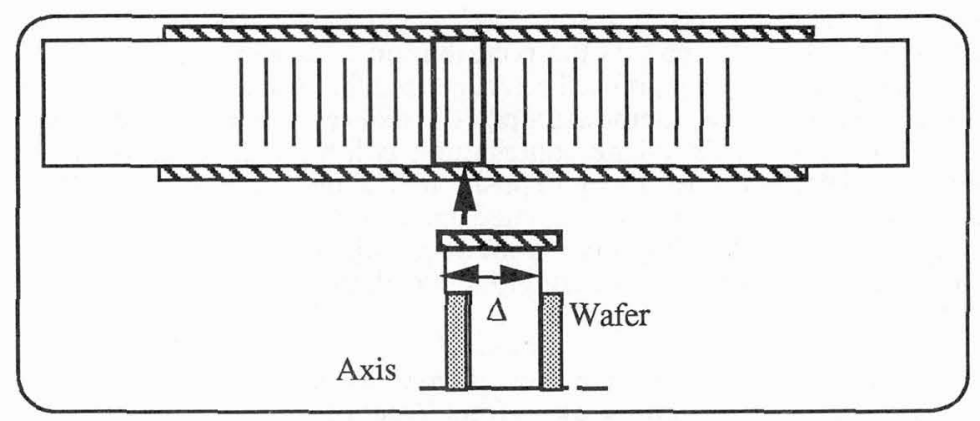

Fig. 1: Modeling zone

\section{2.- 3 Boundary conditions and the periodicity hypothesis /13, 14/}

Boundary conditions on solid surfaces are classical and will not be discussed here. The choice of the entrance conditions in the integration volume is more critical as it is dependent on the history of the gas phase in the upstream part of the reactor. To overcome this difficulty, it has been assumed that far from both ends of the tube, phenomena recur periodically, from an interwafers spacing to the following, i.e. flow, transport processes and chemical phenomena have reached some sort of dynamic equilibrium. For concentrations, the profiles and their axial derivatives have been supposed identical at the entrance and at the exit for silylene and disilane and in similarity for silane (consumed) and hydrogen (produced). This hypothesis will be discussed again in the following.

\section{2.- 4 Examples of results}

Only a few significant results will be described, to demonstrate qualitatively the real nature of some important phenomena.

2.4.1. Deposition of pure silicon from silane: It can be observed on Fig. 2 that the silane contribution, of the order of $60 \AA / \mathrm{min}$, remains practically constant on the whole wafer, which results from the uniformity of the concentration of this reactant in the modeling zone.

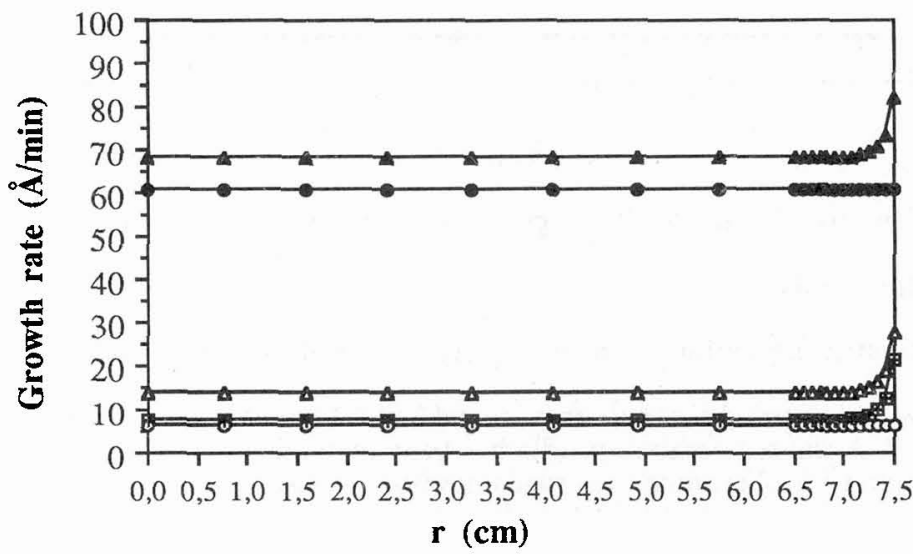

Pure Si Poly

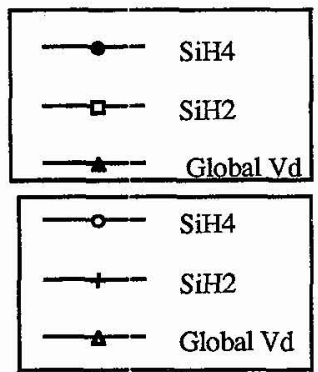

Phosphorus doped poly Si

Fig. 2 : Silicon deposition rates on the downstream side of the entrance wafer

$\mathrm{T}=600^{\circ} \mathrm{C} ; \mathrm{P}=0.1$ Torr ; Silane flow $=200 \mathrm{sccm}$; Interwafers distance $=5 \mathrm{~mm}$;

Wafer diameter $=7.5 \mathrm{~cm}$; Tube diameter $=10 \mathrm{~cm}$ 
2.4.2. Growth rate reduction in presence of phosphine: It has already been indicated that the addition of phosphine strongly inhibits the contribution of silane to the film growth rate. For the corresponding numerical simulation, it has been supposed that silane contribution has been divided by 10. A new calculation has, then, demonstrated $/ 14 /$ that the silylene concentration distribution in presence of phosphine, when the silane contribution is inhibited, remains identical to the profile which had been calculated for pure silicon deposition. The new contribution of the different gaseous species to the layer formation has been calculated and is also presented on Fig. 2. It appears, clearly, that the silylene contribution, less important, introduces slight overthicknesses at the periphery of the wafer and that the global growth rate is strongly reduced, due to the very important inhibition of the silane contribution.

2.4.3. Bull's eye effect: As a consequence, the previously minor silylene contribution becomes now predominant, creating the bull's eye effect (see Fig. 2), that is to say, producing high overthicknesses at the wafer periphery.

2.4.4. Influence of the interwafers distance: Simulation has also demonstrated that an increase of the interwafers distance results in an increase of the silylene concentration and consequently, of the corresponding contribution to the film growth rate (see Fig. 3), that is to say, finally, of the total growth rate. To summarize, numerical simulation reproduces qualitatively all the important phenomena observed when adding a slight percentage of phosphine to silane. Moreover, it suggests that all these effects result from a drastic inhibition of the direct silane deposition contribution leaving the first role to silylene.

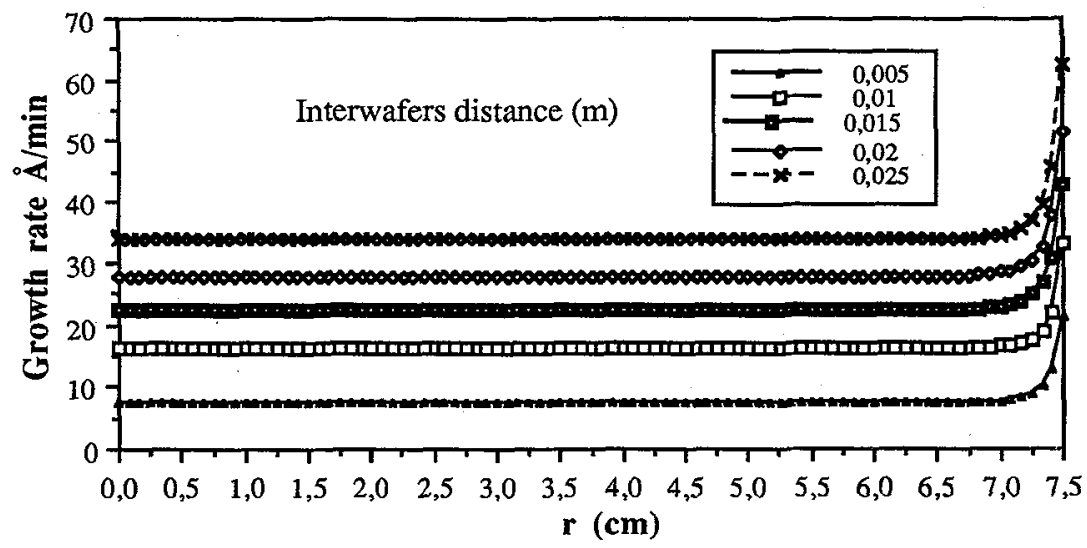

Fig. 3: Silylene contribution to silicon growth rate for different interwafers distances

\section{3.- Experimental study}

\section{3.- 1 In situ phosphorus doped polysilicon deposition without cages}

Experiments have been carried out in a conventional LPCVD reactor, which has been described in detail elsewhere $/ 14 /$. A flat temperature profile has been maintained (at $\pm 0.5^{\circ} \mathrm{C}$ ) over the total wafer load. Pure silane and 5\% phosphine in nitrogen have been used as source gases. The operating conditions of the few experimental runs which will be discussed in the following are presented in table 1. 
Table $1:$ Experimental conditions

\begin{tabular}{|c|c|}
\hline Operating conditions & \\
\hline Temperature $\left({ }^{\circ} \mathrm{C}\right)$ & 622 \\
\hline Pressure $(\mathrm{Pa})$ & 25.6 \\
\hline $\mathrm{SiH}_{4}$ flow $\left(\mathrm{cm}^{3 / \mathrm{min})}\right.$ & 150 \\
\hline $\mathrm{PH}_{3}$ flow $\left(5 \%\right.$ in $\left.\mathrm{N}_{2}\right)\left(\mathrm{cm}^{3 / \mathrm{min}}\right)$ & 60 \\
\hline${\text { Pure } \mathrm{PH}_{3} \text { flow } / \mathrm{SiH}_{4} \text { flow }}^{\text {Wafer diameter }(\mathrm{mm})}$ & 2 \\
\hline Wafers number & 100 \\
\hline Wamber & 58 \\
\hline
\end{tabular}

The test substrates were constituted of silicon wafers on which $1000 \AA$ of thermal silicon dioxide had been grown.

The influence of the interwafers distance and the bull's eye effect at the wafer periphery can clearly be seen on Fig. 4, where three different sets of film growth rate radial variations are presented.

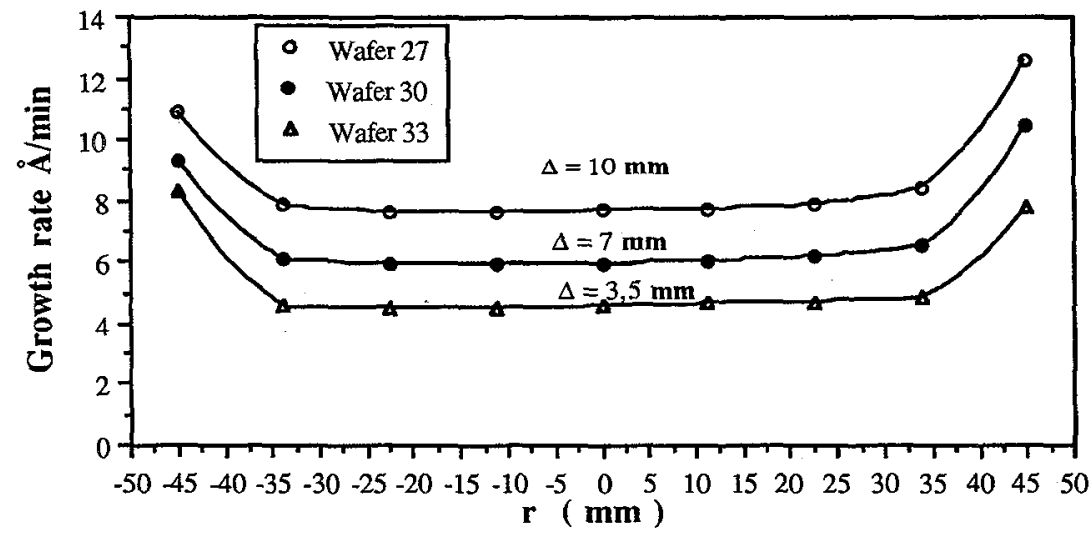

Fig.4: Growth rate vs. radial position for different values of the interwafers distance

The evolution of the growth rate along the reactor has also been measured. Two particular interesting results are presented on Fig.5. They correspond to perfectly identical experimental conditions (see Table 1), except the distance between the reactor front door and the first wafer of the load. For a short distance, the growth rate has been of the order of 6 to $8 \AA / \mathrm{min}$; a $22 \mathrm{~cm}$ increase of this distance has produced a remarkable increase in the growth rate, which has been multiplied by 4 .

To our knowledge, such a result is presented for the first time. It has two very important consequences.

First, it demonstrates that the wafers boat position inside the isothermal region of an industrial reactor must be accurately controlled if reproducible results are to be obtained. In fact, the constraint is probably more critical and we think that what must be maintained constant is the thermal treatment of the entrance silane, before it reaches the first wafer.

Secondly, it strongly suggests that the entrance boundary condition selected in the 2D-model is probably not correct. It seems clear that the silylene and disilane concentrations have never reached, along the wafers line, the periodicity situation which has been supposed, otherwise the results would have been independent of what takes place in the entrance zone. On the contrary, we think that the 
reactor operates with higher concentrations of silylene and disilane, built in the entrance region. These concentrations increase with length and are then slowly consumed along the wafers line (note that both sets of results in Fig. 5 show a slow decrease of the silicon growth rate). The consequence of this is that new modelling developments, with other entrance conditions, must be undertaken in the model.

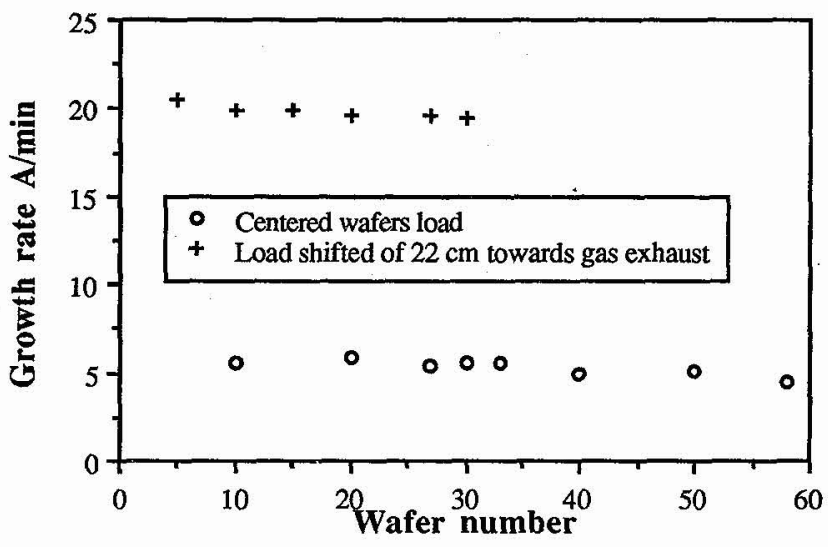

Fig. 5: Longitudinal evolution of silicon growth rate

\section{2- Suppression of the bull's eye effect}

Even if they correspond to a particular case, with a non general entrance condition, the few simulation results presented in this study nevertheless clearly show that the overdeposit at the wafer edge stems from the organization of the silylene concentration profile. A prototype version of a novel wafer cage $/ 16 /$, involving quartz rings placed around each wafer (see Fig. 6) and inserted in a conventional wafer boat, has been tested, the objective of such a cage being to shift the bull's eye effect from the wafer to the ring. This cage is simple to design and is likely to generate fewer solid particles than a usual cage.

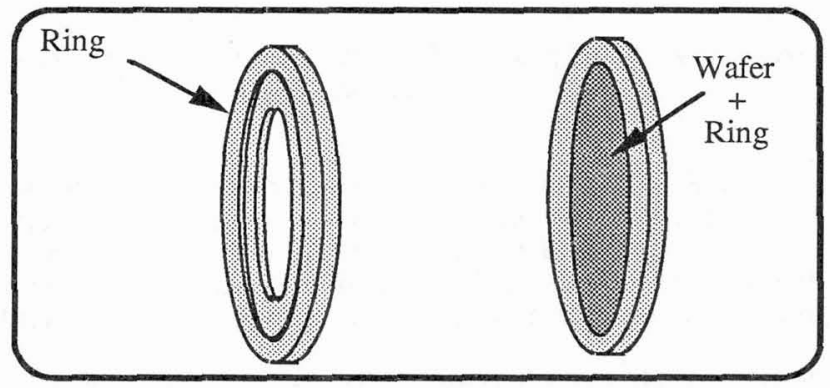

Fig. 6: Principle of the novel wafer cage

Experimental tests have thus been processed in presence of silane $(150 \mathrm{sccm})$ and phosphine (60 sccm). The temperature of the flat zone has been maintained equal to $622^{\circ} \mathrm{C}$ and the total pressure at 25.6 Pa. Of course, as it can be seen on Fig.7, the deposition rates remain low, of the order of 7 to 9 $\AA / \mathrm{min}$; moreover, the influence of the interwafers distance is still evident. But undoubtedly, the most interesting result is the elimination of the bull's eye effect, as the deposit thickness uniformity reaches now acceptable values (see Fig. 7 and table 2) on the wafer. 


\section{4.-Comments and conclusions}

The simultaneous use of experimental analysis and of numerical simulation has helped in developing a better understanding of the phenomena involved in phosphorus in situ doped silicon deposition.

A first comment has to be made on the comparison between experimental and numerical results. If it appears clearly that modelling reproduces qualitatively all the phenomena that have been observed, a quantitative comparison results in important disagreements. Our opinion is that these differences are due to large uncertainties on kinetic data, in particular for homogeneous reactions. We are presently trying to improve this point and will soon be able to produce better numerical predictions.

Our second comment is that the observation of the very strong influence of the wafers load position opens new theoretical needs; a detailed analysis of the entrance zone, where silane begins to react and to produce intermediate products which will be consumed along the wafers line, becomes necessary.

Finally, the first tests of the completely new type of cage we have developed, with peripheral rings, seem encouraging. This cage is very simple to design, either by use of the $2 \mathrm{D}$-model, or by doing a single deposition experiment and measuring the bull's eye thickness, and is likely to produce a low level of particles. Work is presently going on to improve its technological organization and to decrease its cost.

Table 2: Values of the deposit thickness uniformity in presence of the novel wafer cage

\begin{tabular}{|l|l|}
\hline Test wafer position in the load & Mean thickness variations \\
\hline 2 & $2.36 \%$ \\
\hline 12 & $1.43 \%$ \\
\hline 20 & $2.62 \%$ \\
\hline 27 & $2.79 \%$ \\
\hline
\end{tabular}

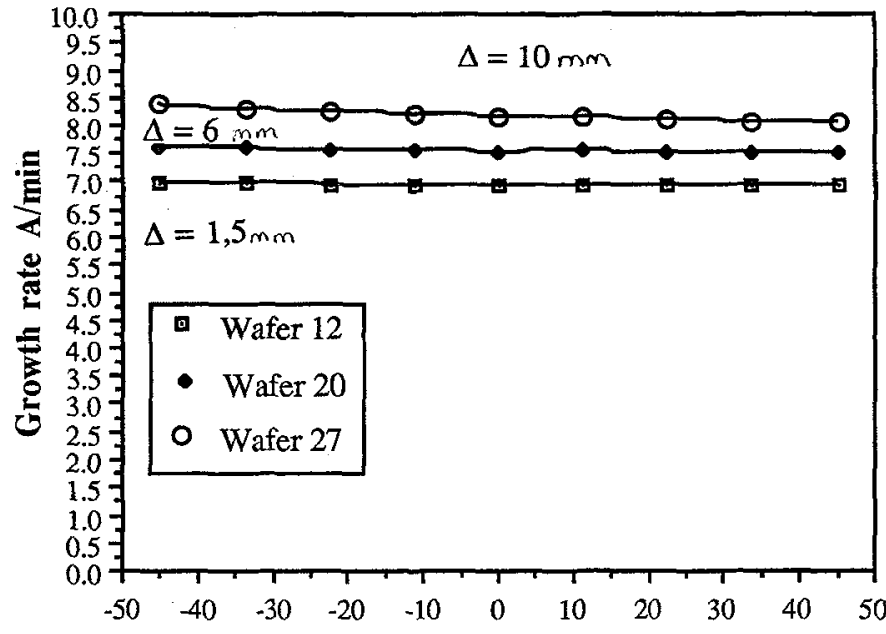

Fig. 7: Radial growth rate variations in presence of the novel wafer-cage 


\section{Acknowledgements}

The authors are indebted to Motorola Inc. for assistance in thickness measurements and to Heraeus Inc. for the design and fabrication of the novel wafers cage.

\section{References}

/1/-Meyerson B.S., Olbricht W., J.Electrochem. Soc., Vol. $131 \mathrm{n}^{\circ} 10$, pp. 2361-1365 (1984)

/2/-Meyerson B.S., Yu M.L., J.Electrochem. Soc., Vol. 131 n $^{\circ} 10$, p. 2367(1984)

/3/-Baudrant A., Sacilotti M., J.Electrochem. Soc., Vol.129 n5, p. 1109 (1982)

/4/- Kurokawa H., J.Electrochem. Soc., Vol.129 n'11, p. 2620 (1988)

/5/-Eversteyn F.C., Put B.H., J.Electrochem. Soc., Vol. 120, p. 106 (1973)

16/- Yeckel A., Middleman S., J.Electrochem. Soc., Vol. 137 n'1, pp.207-212(1990)

17/- Mulder J.G.M., Eppenga P., Hendriks M., Tong J.E., J.Electrochem. Soc., Vol. 137 n 1, p. 273 (1990)

/8/-Jensen K.F., Graves D.B., J.Electrochem. Soc., Vol. 130, pp.1950-1957(1983)

19/-Roenigk K.F., Jensen K.F., J.Electrochem. Soc.,Vol.132 pp.448-454(1985)

/10/-Yeckel A., Middleman S., J.Electrochem. Soc., Vol. 134 n5, pp.1275-1281 (1987)

/11/ Yeckel A., Middleman S., Hochberg A.K., J.Electrochem. Soc., Vol. 136 nº, pp.2038-2049 (1989)

/12/-Azzaro C., Duverneuil P., Couderc J.P., Modeling of pure and in situ doped polycrystalline silicon deposition in LPCVD reactors, To be published in Materials \& Manufacturing Processes

/13/-Couderc J.P., Duverneuil P., Proceedings of the 11th International Conference on CVD-Seattle Oct. 14-19/1990, p. 68 (1990)

14/-Azzaro C., Thèse de Doctorat INPT (21 Février 1991), Analyse et modélisation du fonctionnement des réacteurs de dépôt chimique en phase vapeur: Cas du silicium pur ou dopé in situ /15/-Chang C.A., J.Electrochem. Soc., Vol. 123 n $^{\circ} 8$, pp. 1245-1247 (1976)

/16/-Couderc J.P., Izard J.C., Duverneuil P., "Procédé de réalisation de cages pour le dépôt, dans un réacteur en phase vapeur, de couches minces sur des substrats et, cages obtenues pour la mise en oeuvre de ce procédé", Brevet Européen, n89.10462 du 01/08/1989 